\title{
Residual Stress Analysis After the Induced Martensitic Transformation by Rolling and Tensile Test in the 304L TRIP Steel
}

\author{
Juciane Maria Alves ${ }^{a, b *}$ (), Andersan dos Santos Paula ${ }^{a}$ (), Luiz Paulo Brandao ${ }^{a} \mathbb{C}$ \\ ${ }^{a}$ Instituto Militar de Engenharia, Seção de Engenharia de Materiais, Programa de Pós-Graduação em \\ Ciência dos Materiais, Rio de Janeiro, RJ, Brasil. \\ ${ }^{b}$ Centro Brasileiro de Pesquisas Físicas, Laboratório de Magnetismo Aplicado, Rio de Janeiro, RJ, \\ Brasil.
}

Received: March 29, 2021; Revised: May 12, 2021; Accepted: May 18, 2021

In this work, the residual stress study by XRD was carried out after martensitic transformation of a 304L steel subjected to plastic strain by rolling and tensile test, at room and cryogenic temperatures. This article intents to contribute with the understanding of residual stresses generated by martensitic transformation induced by plastic deformation due to its complexity. From the experimental conditions employed, it was possible to obtain high martensite volumetric fraction and it was possible to observe the influence of existing phases on the performance of residual stress measurements. In general, compressive residual stress was observed for both austenite and martensite phases. The samples rolled at cryogenic temperature showed higher magnitudes of compressive stresses, between -123 and -231 MPa, for martensite volumes between 98 and 100\%. It was also clearly displacement and widening of diffraction line due to the presence of residual macro and microstresses when compared to the as-received material.

Keywords: Martensitic transformation, 304L austenitic stainless steel, residual stress, X-ray diffraction, diffraction line shifts.

\section{Introduction}

The 304L steel, when subjected to plastic strain by tensile, compression and other strain processes/modes, may undergo austenite-martensite transformation $\left(\gamma \rightarrow \alpha^{\prime}\right)$ or $\left(\gamma \rightarrow \varepsilon \rightarrow \alpha^{\prime}\right)$ as a function of stacking fault energy (SFE) ${ }^{1-4}$. The evolution of this phase transformation is strongly influenced by deformation temperature above spontaneous starting martensitic transformation temperature $\left(M_{\mathrm{s}}\right)^{4,5}$. Low temperatures, close to $M_{\mathrm{s}}$, reduce the adiabatic heating during plastic strain ${ }^{5,6}$ and in this way can intensify the martensitic transformation. The $M_{\mathrm{s}}$ estimating, based on empirical equations ${ }^{2,7-9}$, takes into account the chemical composition of alloy and is a positive factor for the occurrence of a more intense transformation, once the chemical composition influences the alloy stability in the austenitic field and defines values for the SFE at this stage ${ }^{1-3}$ (Equation 1). The influence of the residual stresses in the martensitic transformation occurs due to the martensite volumetric expansion of where the difference in free energy associated with volume variation between mother and product phases $\left(\gamma\right.$ and $\left.\alpha^{\prime}\right)$ is altered by tensile and compressive stresses, as well as the shear associated with the transformation, where the internal energy of nuclei formation is altered by shear stresses ${ }^{10}$.

$$
\begin{aligned}
& M_{S}\left({ }^{\circ} C\right)=1305-1665(\% C+\% N)- \\
& 28(\% S i)-33(\% M n)-42(\% C r)-61(\% N i)
\end{aligned}
$$

\footnotetext{
*e-mail: juciane_alves_rj@yahoo.com.br
}

For martensitic transformation in general, the nucleation may be influenced by plastic strain or elastic stresses, as well as previous transformation. Ametallic alloy when subjected to plastic deformation has variations in residual stresses in its extension and high dislocations density. Nucleation in matrix phase is favored in the vicinity of dislocations not because the dislocations are subcritical martensite nucleus but because the transformation energy of a critical size nucleus is modified by the stress ${ }^{10}$. Assuming that the nucleation per unit volume is proportional to the internal strain energy, the speed which the nuclei are formed depends on factors such as alloy chemical composition, strain rate, mechanical stress mode and type of transformed phase ${ }^{11}$. The martensitic transformation induced by elastic stress or plastic deformation is described as a characteristically autocatalytic process, where the increase in the number of martensite embryos increases with the appearance of new nucleation sites due to the imposed elastic or plastic deformation on the material ${ }^{11}$.

Residual stresses are those that remain acting on the component in the absence of external loads and/or temperature gradient. In general, residual stresses are consequences of interactions between deformation, temperature and microstructure as well as the generation of local strain fields by strain-induced martensitic transformation resulting in stress variations in both austenite and martensite phases ${ }^{12}$. The residual stress measurement by X-ray diffraction (XRD) assumes the presence of linear elastic deformation in the crystalline lattice ${ }^{13}$. This fact is based on the principle that when subjecting a polycrystalline material to elastic deformation, the distribution of the lattice strain occurs 
uniformly over long distances from the material. Therefore, the average of lattice planes spacings is changed according to the type and magnitude stress. The diffraction technique does not directly measure the residual stress but it is evaluated based on measuring the variation of the interplanar spacing modified by the stress field presence. The same stress can increase or decrease the interplanar spacing depending on the orientation between the lattice planes and the loading direction ${ }^{14}$. In this way, it is possible to observe diffraction line shifts to greater or fewer values of two-theta as a function of fewer or greater interplanar spacing. Displacement and widening peak refer to the presence of residual macro or microstresses and this can coexist when the material is plastically deformed ${ }^{14}$.

With this investigation was possible to obtain samples with high martensite volumetric percentage up to a $100 \%$ martensitic. From this, the residual stress study by X-ray diffraction was carried out focusing on the measurements performed in the austenite and martensite phases. In general, compressive residual stress was observed in both phases. As a function of the the influence of existing phases it was clearly observed diffraction line shifts.

\section{Experimental Procedure}

The material for this investigation consisted of 304L austenitic stainless steel plates produced by two different processes: hot rolling (HR) and cold rolling/annealing (CRA) with thicknesses of 6.37 and $3.0 \mathrm{~mm}$ and average diameter grain size of 8.99 and $9.37 \mu \mathrm{m}$, obtained by electron backscattered diffraction (EBSD) analysis with estimated standard deviation 0.01 , respectively ${ }^{15}$. The chemical compositions are shown in Table 1.

The induced martensitic transformation by rolling processing on the HR samples was compared to those obtained by uniaxial tensile test imposed to HR and CRA samples. The experiments were performed at two different temperatures, $298 \mathrm{~K}$ (room temperature) and $155 \mathrm{~K}$ (cryogenic temperature). The cryogenic temperature was chosen using Equation 1, which gives the $M_{s}$ temperature as a function of the material chemical composition and the samples were placed in liquid nitrogen for approximately 3 minutes, before each pass. The applying rolling thickness reductions were $20,40,60$ and $80 \%$ and tensile deformations were performed up to 24 and $47 \%$, which is quite similar to the effective strain of 20 and $40 \%$ in rolling. For uniaxial tensile test at cryogenic temperature, the samples were placed in liquid nitrogen for approximately 3 minutes and the chamber was kept in the same temperature during the tests. In order to show and discuss the results, a short nomenclature was established as showed on Figure 1: first highlighting the condition as-received (HR - Hot Rolling and CRA - Cold Rolling/Annealing), the temperature ( $\mathrm{R}$ - Room temperature and C - Cryogenic temperature), deformation mode ( $\mathrm{R}$ Rolling and $\mathrm{T}$ - Tensile test) and finally the deformation percentage $(20,40,60$ and $80 \%$ for rolling and 24 and $47 \%$ for uniaxial tensile) imposed. In order to investigate the profile of the residual stress, the thicknesses of samples were reduced by $3 / 4$ and $1 / 2$ via grinding the samples using $120,220,400,600,800$ and 1200 grit papers, before being subjected to final electrolytic polishing (perchloric acid solution $20 \%$ in ethyl alcohol as electrolyte, voltage used in the equipment was $20 \mathrm{~V}$ ). The polishing time of the samples was between 7 and 10 seconds, being the smaller time for larger martensite volumes fractions. The residual stress measurements of the austenite and martensite phases were performed separately (samples dimensions were $25 \mathrm{~mm}$ in length and $20 \mathrm{~mm}$ in width). The measurements were performed using PANalytical's X'PERT PRO MRD diffractometer, using the psi geometry method, which consists of measuring the variation of interplanar spacing from different angular positions of the sample, relating them to the $\sin ^{2}$ of these angles. All residual stress results presented in this work refer to the stresses measured in phi $45^{\circ}$, in this position we have the average between the main stresses $\left(\sigma_{1}\right.$ and $\left.\sigma_{2}\right)$. The samples were analyzed with cobalt radiation $(\mathrm{Co}-\mathrm{K} \alpha)$ and the rolling direction placed parallel to the $\mathrm{Y}$ axis of the goniometer. The X'Pert stress software was used for the post-processing of the stress measurements. For the quantification of phases, the Rietveld method was used with the Topas software.

\section{Results and Discussion}

The residual stress profiles of the austenite phase in the HR and CRA samples, determined for measurements at sample positions: surface and $3 / 4$ and $1 / 2$ of the original thicknesses are shown in Figure 2.

The HR sample (Figure 2a) showed greater residual stress variation compared to CRA (Figure 2b). The $\alpha$ 'martensite volume fraction evaluated by XRD along the thickness of these samples on surface, and on $3 / 4$ and $1 / 2$ of the original thickness was equal to $0.8,0.8$ and $0.9 \%$ and $0.5,1.4$ and $2.1 \%$, respectively (Table 2 ). The difference in the compressive residual stresses in these samples resulted not only of the martensite volume variation, but also because of the previous thermomechanical processing applied on the material. Residual stress tendency of the hot rolling sample was quite different of the annealled cold rolled material. One can observed that for the first material a decrease in compressive stress from the surface to the center samples. In the annealed sample the residual stress was approximately constant along the material thickness.

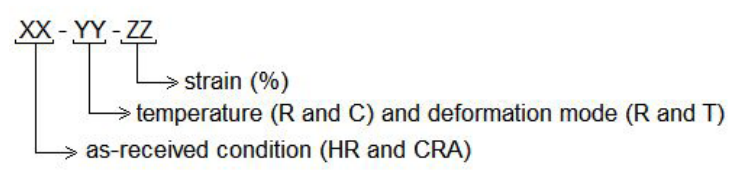

Figure 1. Short nomenclature established for samples in study.

Table 1. Chemical composition of 304L steel (weight \%).

\begin{tabular}{cccccccccc}
\hline 304L Steel & $\mathrm{C}$ & $\mathrm{Mn}$ & $\mathrm{Si}$ & $\mathrm{P}$ & $\mathrm{S}$ & $\mathrm{Cr}$ & $\mathrm{Ni}$ & $\mathrm{Mo}$ & $\mathrm{N}$ \\
\hline $\mathrm{HR}$ & 0.0196 & 1.2617 & 0.4911 & 0.0378 & 0.0008 & 18.0363 & 8.0837 & 0.1351 & 0.0509 \\
\hline CRA & 0.0196 & 1.2586 & 0.5729 & 0.0382 & 0.0002 & 18.0819 & 8.0045 & 0.1563 & 0.0422 \\
\hline
\end{tabular}


Table 2. Martensite volume of as-received samples and after rolling at room temperature.

\begin{tabular}{|c|c|c|c|c|c|c|c|}
\hline \multirow{2}{*}{$\begin{array}{l}\text { Samples as- } \\
\text { received }\end{array}$} & \multicolumn{3}{|c|}{$\alpha^{\prime}\left(V^{\prime} \%\right)$} & \multirow{2}{*}{$\begin{array}{l}\text { Samples room } \\
\text { rolling }\end{array}$} & \multicolumn{3}{|c|}{$\alpha^{\prime}\left(V^{\circ} \%\right)$} \\
\hline & Surface & $3 / 4$ & $1 / 2$ & & Surface & $3 / 4$ & $1 / 2$ \\
\hline $\mathrm{HR}$ & 0.8 & 0.8 & 0.9 & HR-RR-20 & 35 & 32 & 24 \\
\hline CRA & 0.5 & 1.4 & 2.1 & HR-RR-80 & 96 & 88 & 79 \\
\hline
\end{tabular}

Table 3. Martensite volumes after cryogenic rolling and after effective strain in rolling and tensile test at room temperature.

\begin{tabular}{|c|c|c|c|c|c|}
\hline \multirow{2}{*}{$\begin{array}{l}\text { Samples cryogenic } \\
\text { rolling }\end{array}$} & \multicolumn{2}{|c|}{$\alpha^{\prime}(\mathrm{V} \%)$} & \multirow{2}{*}{$\begin{array}{c}\text { Samples effective } \\
\text { strain }\end{array}$} & \multicolumn{2}{|c|}{$\alpha^{\prime}(\mathrm{V} \%)$} \\
\hline & Surface & $1 / 2$ & & Surface & $1 / 2$ \\
\hline HR-CR-20 & 66 & 95 & \multirow{2}{*}{ HR-RR-20 } & \multirow{2}{*}{35} & \multirow{2}{*}{24} \\
\hline HR-CR-40 & 98 & 99 & & & \\
\hline HR-CR-60 & 100 & 100 & \multirow{2}{*}{ HR-RT-24 } & \multirow{2}{*}{8} & \multirow{2}{*}{4} \\
\hline HR-CR-80 & 100 & 100 & & & \\
\hline
\end{tabular}
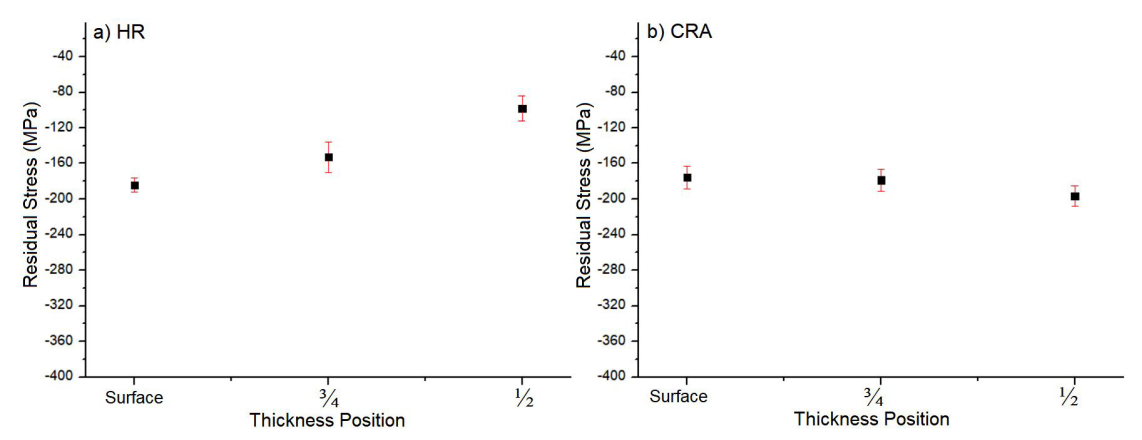

Figure 2. Residual stress profiles of the austenite phase as function thickness position HR (a) and CRA (b) samples.
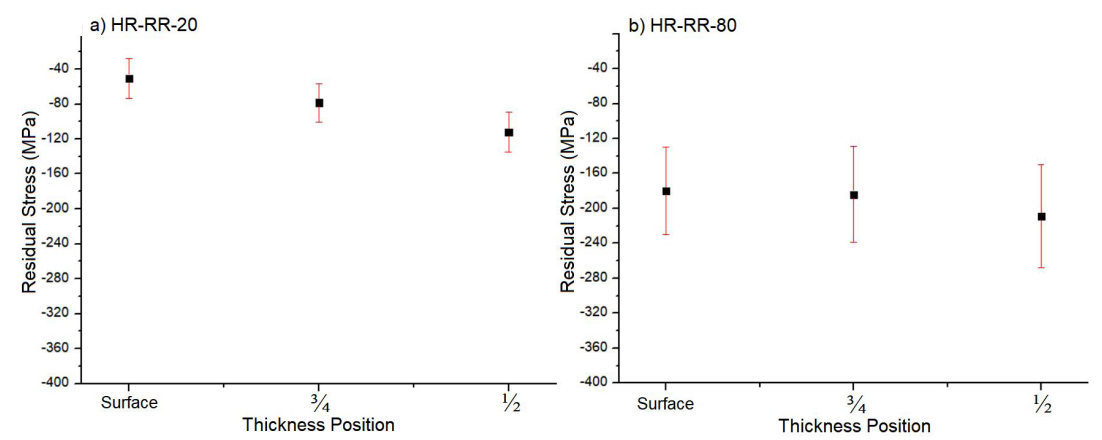

Figure 3. Residual stress profile of the austenite in HR-RR-20 sample (a) and $\alpha$ '-martensite phase in HR-RR-80 sample (b).

The residual stress of HR samples was again evaluated after rolling at room temperature. Depending on the intensity of the martensitic transformation in rolling, the austenite or martensite phases stress was measured. In samples with $\alpha^{\prime}$-martensite percentage up to $35 \%$, it was only possible to measure austenite residual stress, because below this percentage there was a lot of scattering in the measurement and consequently, high standard deviation. For samples with $\alpha^{\prime}$-martensite volume fraction equal or higher than $66 \%$, it was only possible to measure the residual stress of this phase, below this martensite percentage occurred as mentioned above. For this reason, the austenite residual stress was measured in HR-RR-20 sample and the martensite residual stress was measured for the HR-RR-80 sample. It was observed compressive residual stress in both phases and high magnitude in half thickness of the samples (Figure 3). It can be also noted a change in residual stress tendency when compare to HR sample (Figure 2a). The difference in residual stress magnitude in some measures was not quite significant when the standard deviation is taken in account. The $\alpha$ '-martensite volume in these samples corresponded to $(35,32$, and $24 \%)$ and (96, 88 and $79 \%$ ), respectively, on surface, $3 / 4$ and $1 / 2$ of the original thickness (Table 3). According to Fisher and Turnbull ${ }^{10}$, the martensitic nucleation occurs heterogeneously due to the dislocation density and residual stress fields since the formation energy of a critical size nucleus is modified by stress and not because the dislocations are subcritical martensite nucleus. The $\alpha^{\prime}$-martensite formation is more susceptible to strain variation in the normal direction on rolling ${ }^{6}$. Nagy et al. ${ }^{16}$ reported that the variation in the quantitative assessment of martensitic transformation depending on the samples plane/section.

The HR samples were also subjected to cryogenic rolling for reductions of 20, 40, 60 and $80 \%$. It was only possible to measure the martensite residual stress (Figure 4) due to high volumetric fractions of this phase for the same reasons 
already mentioned. The analyses were performed on the surface and half thickness of the samples. The $\alpha$ '-martensite volume fractions of these samples were $66,98,100$ and $100 \%$ at the surface and $95,99,100$ and $100 \%$ at the half thickness, respectively (Table 3).

As can be seen in Figure 4, samples presented tensile and compressive residual stresses due to the rolling reduction and the martensite volume (Table 3 ). This variation of stress state can be understood not only in terms of the phase transformation nature occurred but mainly by the mechanical nature of the deformation process. So, the influence of the martensite volume fraction and the aspect of the stress distribution in the plate thickness after rolling on the stress state were evaluated (Figure 5). The presented stress state in cold rolled plates can be understood through the characteristic aspects on their edges ${ }^{17}$. As can be noted in Figure 5, the mechanical residual stresses on the suface and center of rolled material is correlated to their edge profiles. In the present case, the plate edges after rolling presented an aspect similar to Figure 5b, characterizing the probability of existing a compressive stress state in the center and tensile one at the surface. In this case, the material undergoes greater expansion in the central region and the friction between the rolling cylinders and material surface, in order to inibihit this phenomenon, imposed a compressive residual stress on the material surface. This way, as the residual stresses are self-balanced, the central region tends to lug the nearby regions, leaving them under tensile stresses. Plate with edge profiles similar to Figure 5c shows the opposite trend, tensile stresses on the center and compressive stress on the surface. The aspect of stress distribution in the rolled plate is associated with the relationship between the length of

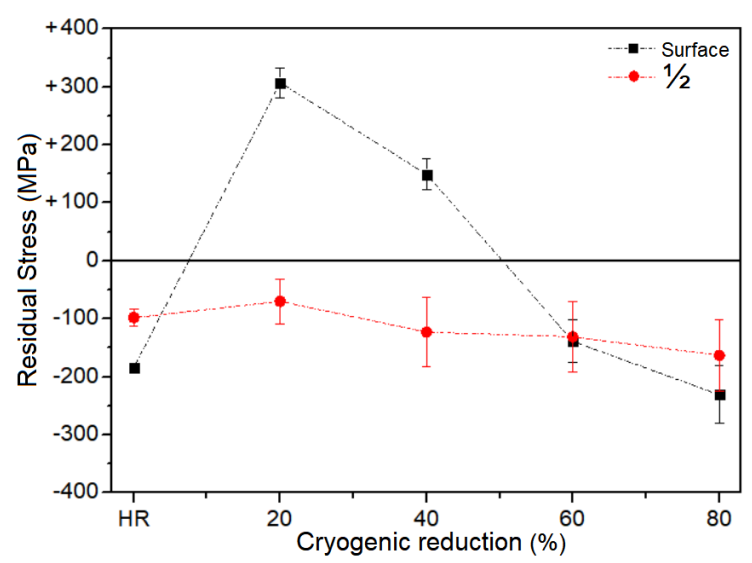

Figure 4. Residual stress profile of the $\alpha^{\prime}$-martensite phase in cryogenic rolling samples: HR-CR-20, HR-CR-40, HR-CR-60 and HR-CR-80. the rolling cylinder contact arc with the plate in respect to its initial height ${ }^{17}$.

So, in light of that analysis, the influence of the martensite volume fraction and the aspect of stress distribution in the plate thickness after cold rolling on the stress state were evaluated. As mentioned, the presented stress state in rolled plates can be correlated to their edge shape. Through the understanding of the mechanical stresses distribution after rolling, the results of the austenite and martensite residual stresses of the plates with 20 and $80 \%$ reductions (Figure 3 ) showed consistency. The HR sample that initially presented only compressive stress, after subjected to $20 \%$ reduction (HR-RR-20), compressive stresses were introduced in the central region and tensile stresses on the surface. The stress on the martensite of the $80 \%$ reduced sample (HR-RR-80) presented a behavior similar to that observed in the $20 \%$ reduced one, where a higher magnitude compressive stress was observed at half thickness. In the HR-RR- 80 sample, the stress magnitude at half thickness was greater than the HR sample (Figure 2) and there was less variation in the stress values, probably due to smaller plate thickness.

The cryogenic temperature rolled samples presented tensile and compressive stresses as can be observed in Figure 4 . Those with 20 and $40 \%$ reduction showed tensile stress on the surface with magnitudes close to 300 and $160 \mathrm{MPa}$, respectively. Based on the plate aspects, the mechanical tensile stress introduced in regions near the surface exceeded the magnitude of the compressive stress present in the HR sample. However, at half thickness the stress was compressive. For the samples with 60 and $80 \%$ reductions, there was a full phase transformation, i.e. $100 \%$ $\alpha$ '-martensite. These samples showed compressive stress both on the surfaces and at half thicknesses. For these totally martensitic samples, probably the residual stress was largely introduced by phase transformation. Likely, this material presented higher surface hardness than HRCR-20 and HR-CR-40 samples, thus, less friction with the rolling cilynders. Graphically, there is a significant oscillation of the measurements performed on the surface, but at half thickness the stresses showed less variation as a function on the $\alpha$-martensite volume fraction and increase in plastic strain. With the exception of the as-received sample $\left(0.8 \% \alpha^{\prime}\right)$ and the one with $20 \%$ reduction $\left(66 \% \alpha^{\prime}\right)$, the others showed $\alpha^{\prime}$-martensite volume fraction quite close (between 98 and $100 \%$ ). High martensite volume fraction in cryogenic rolling was also obtained by Zheng et al. ${ }^{18}$ and Singh et al. ${ }^{19}$ with 304 steel. The $M_{s}$ temperature of the material under study $(150 \mathrm{~K})$ was estimated from its chemical composition. Therefore, with the supercooling of the material, probably stress-assisted nucleation of martensitic transformation occurred between the $M_{s}$ and $M_{s}^{\sigma}$ temperatures ${ }^{8,20}$. After the application of the rolling stress, due to mechanical energy,

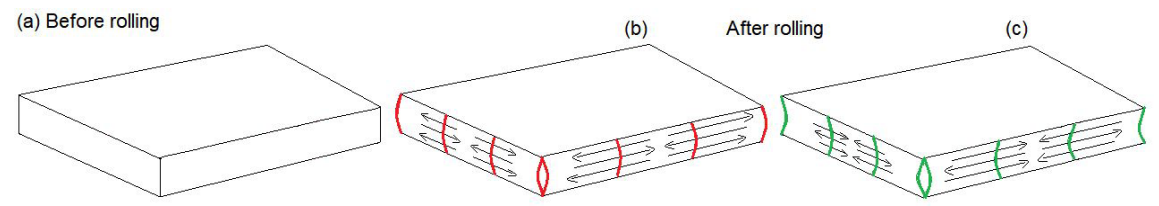

Figure 5. Characteristic aspects of the edges of rolled sheets: (a) before rolling and (b, c) possibilities after rolling. 

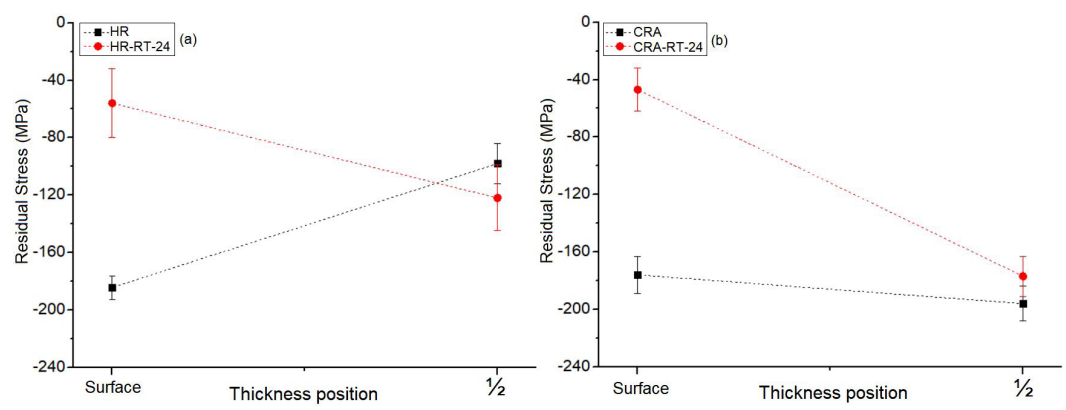

Figure 6. Comparison on the residual stresses of the austenite phase between (a) HR and (b) CRA samples, both in as-received condition and after $24 \%$ deformed in tensile test at room temperature.

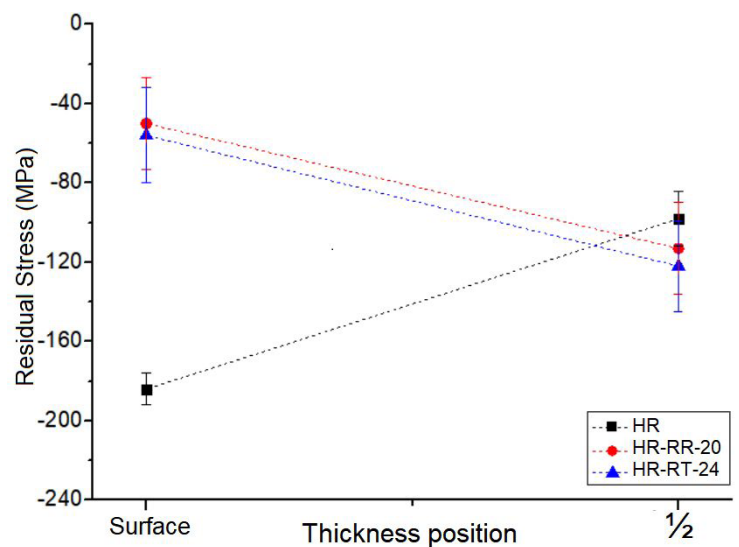

Figure 7. Comparison of residual stresses of the austenite phase among HR samples in as-received condition and after rolling and tensile test at room temperature.

it was possible to promote total martensitic transformation between $M_{d 30}$ and $M_{d}$ temperatures. With the stress-induced nucleation, the martensite formation was favored instead of the dislocation generation, in austenite regions, a behavior that possibly occurred with strain-assisted nucleation of martensitic transformation between $M_{d 30}$ and $M_{d}$ in rolling at room temperature.

The residual stress of the austenite phase for the samples pulled up to $24 \%$ strain at room temperature (HR-RT-24 and CRA-RT-24) are shown in Figure 6. The measurements were performed on the sample surfaces and half thicknesses.

As can be noted in Figure 6, samples with different initial thermomechanical processing showed similar behavior with compressive residual stresses after tensile test. It can be verified a higher magnitude compressive stress at half thickness of these samples. From results presented in Figure 6, one can note that the tensile stresses added after $24 \%$ deformation decreased the stress magnitude present in the as-received samples, HR and CRA. However, the stress became more compressive from the surface to half thickness, where the values kept about the ones of the asreceived samples. Higher magnitude of compressive stress was observed at half thickness of the CRA-RT-24 sample, Figure $6 \mathrm{~b}$, and it also presented lower standard deviation than HR-RT-24 sample. In general, the residual stress state behavior was quite similar for both samples.
Comparing the samples with the similar effective strains, $20 \%$ deformations in rolling (HR-RR-20) and $24 \%$ in tensile test (HR-RT-24), one can note that both presented the same behavior with increasing compressive stress of the austenitic phase from the surface and to half thickness (Figure 7). The $\alpha$ 'martensite volume fraction of these samples corresponded to 35 and $24 \%$ for rolled samples and 8 and $4 \%$ for tensile tested ones, respectively (Table 3 ). Nevertheless, the stress values were quite similar (-50 and $-113 \mathrm{MPa})$ and (-56 and $-122 \mathrm{MPa})$, as shown in Figure 7. Thus, for the material with the same condition of previous mechanical processing subjected to same effective strains in the different deformation modes and with different martensite contents, the same residual stress state was observed and with close values. Supposedly, the rolling and tensile stresses overlaped the stresses generated by the strain-induced martensitic transformations.

As can be observed, for most samples after they are being deformed by rolling and tensile test, the austenite and $\alpha$ '-martensite residual stresses measured by XRD showed that the compressive residual stress was predominant. Only in two samples, with 20 and $40 \%$ reductions in cryogenic rolling, a tensile residual stress was detected in surface analyses, but a compressive stress was detected at half thickness of these samples. The residual stress analyzes showed consistency with the rolled plate aspects, as well as the loading type of tensile test and considering the stresses in the as-received samples. There is no way to dissociate residual stresses of plastic deformation processes from those resulting of martensitic transformation when it comes through the induced phase transformation by plastic deformation. In general, residual stresses are consequence of interactions among strain, temperature and microstructure ${ }^{12}$. In the literature approaches ${ }^{12,21-24}$ there is no single definition to the residual stresses state in TRIP steel after martensitic transformation. Taran et al..$^{21-23,25}$ investigated the residual stresses in AISI 321 steel using a neutron diffraction technique, after fatigue test. Taran et al. ${ }^{21,22}$ observed compressive stress for austenite and tractive stress for martensite, which decreased in magnitude with the martensite volume increases. According to author, the plastic deformation stresses may have exceeded those of the phase transformation and were observed in the results. In the continuation of his investigation, TARAN $^{23}$ observed from total stresses calculation, the austenite phase in compression, while the martensite phase would be in balanced tractive stress of greater magnitude for smaller volumetric fraction. Investigating the distribution 
of radial stresses, TARAN ${ }^{25}$ observed hydrostatic stress for austenite in its majority and compressive stress for martensite. Papula et al. ${ }^{12}$ studied the residual stresses from the $(\gamma \rightarrow \alpha$ ') transformation in some austenitic stainless steels after delayed cracking. The authors mentioned that for plastically deformed dual-phase materials, the harder phase presents tractive stress and the softer phase compressive stress. The results showed tensile residual stresses in both phases. Thus, the residual stresses study from the strain-induced martensitic transformation is complex due to the interaction among the deformation process stresses and those resulting from phase transformation ${ }^{21,22}$, as well as, due to the intrinsic characteristics of each phase, such as elastic properties and specific volume $e^{21-23,25,26}$.
The austenitic and martensitic phases peaks, corresponding to $\gamma(220)$ and $\alpha^{\prime}(211)$ planes, were analyzed regarding the occurrence of diffraction line shift in relation to as-received samples. The Figures 8 and 9 show the behavior of the $\gamma$ and $\alpha$ ' peaks after rollings and tensile tests at both room and cryogenic temperatures. The circle in some graphs highlight the original positions of the as-received sample peaks.

The HR samples after rolling and tensile test at room and cryogenic temperatures, Figures 8 and 9, presented the following effects on diffraction peaks regarding to the as-received samples: (i) accentuated widening and displacement after rolling, Figure 8b and 8d; and (ii) accentuated displacement with widening after tensile test, Figure $9 \mathrm{~b}$ and $9 \mathrm{f}$. The austenite peaks showed some displacement and widening but less

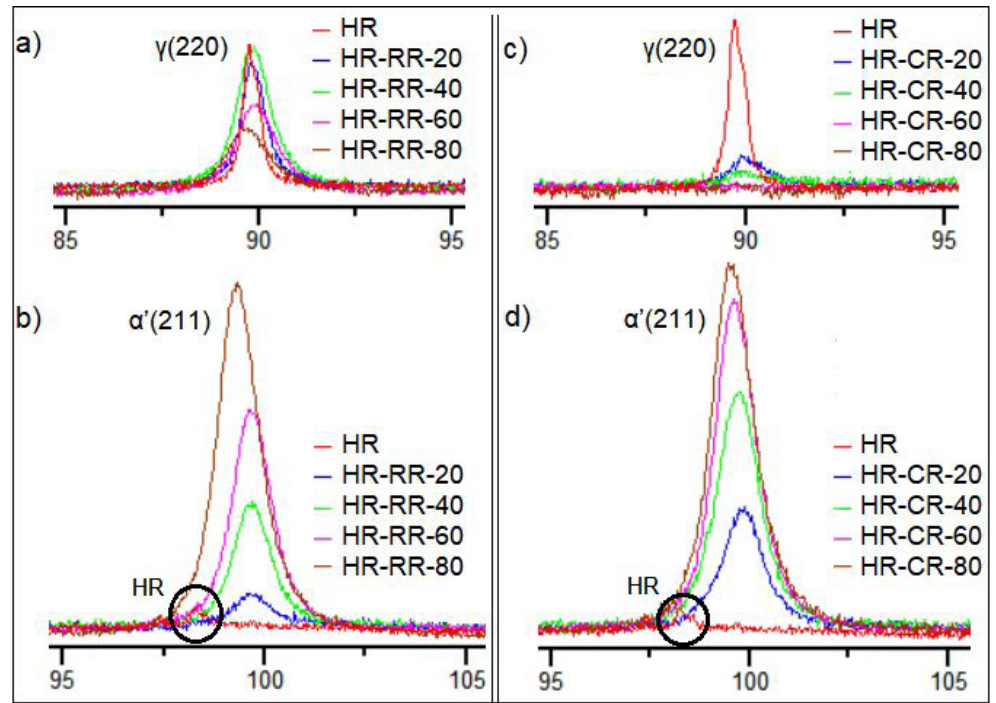

Figure 8. Displacement and/or widening peaks ( $\gamma$ and $\alpha^{\prime}$ ) after martensitic transformation at $298 \mathrm{~K}$ (a and b) and $155 \mathrm{~K}$ (c and d) by rolling.

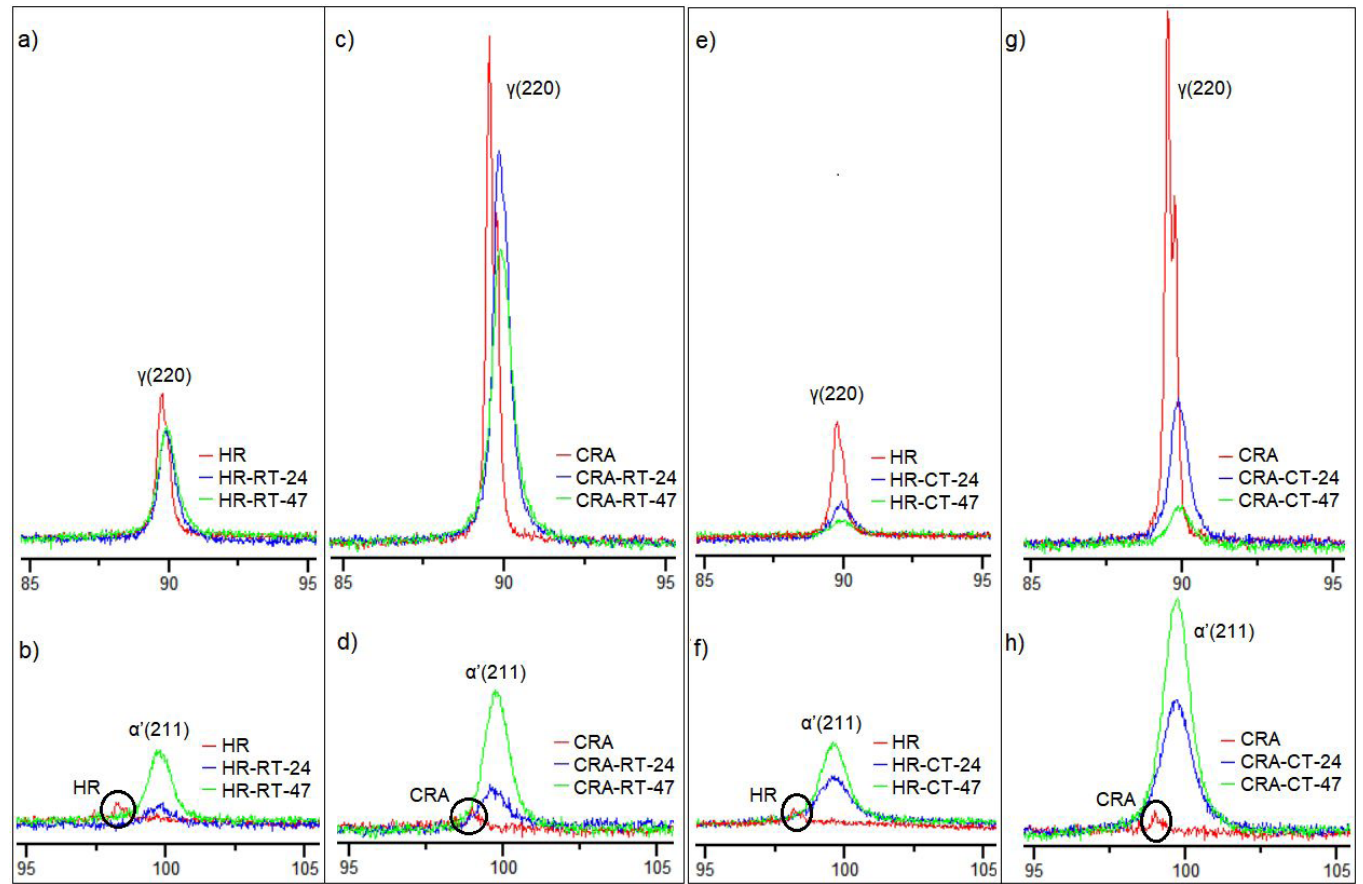

Figure 9. Displacement and/or widening peaks ( $\gamma$ and $\alpha^{\prime}$ ) after martensitic transformation at $298 \mathrm{~K}$ (a-d) and $155 \mathrm{~K}$ (e-h) by tensile test. 
expressive in relation to those of the martensite phase. Among the samples submitted to tensile test in HR and CRA conditions, the HR ones presented a more intense displacement of the peaks Figure $9 \mathrm{~b}$ and $9 \mathrm{f}$. These results show coherence as a function of existing macrostress state in the material, where the presence of compressive stress perpendicular to reflecting planes promotes a decrease in interplanar spacing, what relates to diffraction line displacement ${ }^{14}$. On the other hand, peak widening occurs by microstress resulting from the presence of nonuniform strain, where the same grain may present regions with different interplanar spacings, and the sum of these causes the diffraction line widening ${ }^{14}$. As can be drawn out of the results, displacement and widening of diffraction peaks appeared from induced martensitic transformation by rolling and tensile test. This behavior is in accordance to the literature ${ }^{14}$, because for the material plastically deformed the occurrence of displacement and widening of peaks may coexist.

Some investigations show ${ }^{27-30}$ that different components of the crystallographic texture can be developed by the austenite and martensite phases in TRIP steel and that these are strongly influenced by plastic strain mode ${ }^{27,28}$. In the present study, the occurrence of crystallographic texture was observed, mainly for the highest levels of plastic strain. For the phase quantification, the texture effect was corrected/minimized by refinement of the Preferred Orientation by the Rietveld method using Topas software. For residual stress analysis, this effect was corrected/minimized by refinement of the Lorentz Polarization in the X'Pert-Stress software. The correction of the effect of crystallographic texture was carried out for both phases and the decrease of the GOF (goodness of fit) was clearly observed for the phase quantifications, as well as the decrease of the standard deviation for residual stress measurements.

With this study, it was generally observed that a greater magnitude of residual stress was related to a greater $\alpha$ 'martensite volume of samples submitted to plastic deformation via thickness reduction in rolling. For sample rolled at room temperature, with $80 \%$ reduction, $\alpha$ '-martensite volumes between 96 and $79 \%$ and residual stress between -180 and -209 MPa were observed for analyses carried out on the surface, $3 / 4$ and $1 / 2$ thickness (Figure 3 ). The samples rolled at cryogenic temperature showed higher magnitudes of compressive stresses, between -123 and $-231 \mathrm{MPa}$, for martensite volume fractions of between 98 and $100 \%$ with analyses carried out on the surface and $1 / 2$ thickness.

\section{Conclusions}

A 304L stainless steel with TRIP effect received in two different started conditions, for this study, as hot rolled and as cold rolled and annealled was submitted to the following deformation modes: rolling and tensiles test at room and cryogenic temperatures. During deformation, the martensitic phase transformation was induced. The final residual stresses that have origin in both deformation and phase transformation were measured via XRD and the results conducted to these conclusions:

- In samples with $\alpha^{\prime}$-martensite volume up to $35 \%$ it was only possible to measure residual stress of the austenite phase and in samples with $\alpha$ '-martensite volume equal or greater than $66 \%$ it was only possible to measure the residual stress of this phase;

- The residual stresses measured in the austenite and $\alpha$ '-martensite phases after rolling and tensile test resulted from the interaction among stresses arising of the deformation process and those developed by the martensitic transformation itself;

- In general, a predominance of compressive residual stress was observed, mainly at half thickness of the samples;

- $\quad$ For the materials in the same as-received conditions submitted to different deformation modes, rolling and tensile test, with similar effective strains, the same residual stress state was found and with close stress values;

- It was observed that, supposedly, the rolling and tensile stresses overlap the stresses generated by the strain-induced martensitic transformation;

- The cryogenic temperature intensified the martensitic transformation. However, the magnitude of the resulting residual stress depends on the interaction of these phase transformation stresses with those involved in the deformation process;

- It was clearly observed the diffraction line shift after martensitic transformation due to the presence of residual macro and microstresses in the material.

\section{Acknowledgements}

The authors thank Aperam South America for supplying the material, FAPERJ for a Doctorate scholarship and CNPq for a research productivity grant (PQ-2), processes 307798/2015-1 and 312313/2018-7. Prof. Luiz Paulo Brandao also thanks the Brazilian Agency $\mathrm{CNPq}$ for the research productivity grant (PQ-2), process 308209/2019-2.

\section{References}

1. Shen YS, Li XX, Sun X, Wang YW, Zuo L. Twinning and martensite in a 304 austenitic stainless steel. Mater Sci Eng A. 2012;552:514-22.

2. Kaoumi D, Liu J. Deformation induced martensitic transformation in 304 austenitic stainless steel: in-situ vs. ex-situ transmission electron microscopy characterization. Mater Sci Eng A. 2018;715:73-82.

3. Mallick P, Tewary NK, Ghosh SK, Chattopadhyay PP. Effect of cryogenic deformation on microstructure and mechanical properties of 304 austenitic stainless steel. Mater Charact. 2017;133:77-86.

4. He J, Yuan F, Yang M, Zhou L, Jiao S, Wu X. Exceptional tensile properties under cryogenic temperature in heterogeneous laminates induced by non-uniform martensite transformation and strain delocalization. Mater Sci Eng A. 2020;791:139780.

5. Zheng $\mathrm{C}, \mathrm{Yu} \mathrm{W}$. Effect of low-temperature on mechanical behavior for an AISI 304 austenitic stainless steel. Mater Sci Eng A. 2018;710:359-65.

6. De AK, Murdock DC, Mataya MC, Speer JG, Matlock DK. Quantitative measurement of deformation-induced martensite in 304 stainless steel by X-ray diffraction. Scr Mater. 2004;50(12):1445-9.

7. Cina B. Effect of cold work on the gamma-alpha transformation in some Fe-Ni-Cr alloys. J Iron Steel Inst. 1954;177:406-22.

8. Angel T. Formation of martensite in austenitic steels. J Iron Steel Inst. 1954;5:165-74. 
9. Hedayati A, Najafizadeh A, Kermanpur A, Forouzan F. The effect of cold rolling regime on microstructure and mechanical properties of AISI 304L stainless steel. J Mater Process Technol. 2010;210(8):1017-22.

10. Fisher JC, Turnbull D. Influence of stress on martensite nucleation. Acta Metall. 1953;1(1-5):310-14.

11. Shin CH, Ha TK, Chang YW. Kinetics of deformation induced martensitic transformation in a stainless steel 304L. Scr Mater. 2001;45(7):823829.

12. Papula S, Talonen J, Hanninen H. Effect of residual stress and straininduced $\alpha^{\prime}$-martensite on delayed cracking of metastable austenitic stainless steels. Metallurgical and Materials Transactions. 2014;45(3):1238-46.

13. Withers PJ, Bhadeshia HKDH. Overview: residual stress part 1- measurement techniques. Mater Sci Technol. 2001;17(4):35565.

14. Warren BE, Averbach BL. The effect of cold-work distortion on X-ray patterns. J Appl Phys. 1950;21(6):595-9.

15. Alves JM, Brandão LP, Paula AS. Mechanically induced martensitic transformation of hot rolled and annealed 304L austenitic stainless steel at room and cryogenic temperatures. Mater Res. 2019;22(Suppl. 1):e20190150.

16. Nagy E, Mertinger V, Tranta F, Sólyom J. Deformation induced martensitic transformation in stainless steels. Mater Sci Eng A. $2004 ; 378(1-2): 308-13$

17. Hosford WF, Caddell RM. Metal forming mechanics and metallurgy. Cambridge: Cambridge University Press; 2007.

18. Zheng C, Liu C, Ren M, Jiang H, Li L. Microstructure and mechanical behavior of an AISI 304 austenitic stainless steel prepared by cold- or cryogenic-rolling and annealing. Mater Sci Eng A. 2018;724:260-8.

19. Singh R, Sachan D, Verma R, Goel S, Jayaganthan R, Kumar A. Mechanical behavior of 304 Austenitic stainless steel processed by cryogenic rolling. Mater Today Proc. 2018;5:16880-6.

20. Olson GB, Cohen M. A mechanism for the strain-induced nucleation of martensitic transformation. J Less Common Met. 1972;28(1):107-18.
21. Taran YV, Daymond MR, Schreiber J. Residual stress analysis of fatigued austenitic stainless steel. J. Neutron Res. 2003;11(4):25561.

22. Taran YV, Daymond MR, Schreiber J. Interplay of stresses induced by phase transformation and plastic deformation during cyclic load of austenitic stainless steel. Physica B. 2004;350(13):98-101. http://dx.doi.org/10.1016/j.physb.2004.04.004.

23. Taran YV, Balagurov AM, Sheverev SG, Bomas SH, Korsunsky AM. Investigation of in-plane biaxial low cycle fatigued austenitic stainless steel aisi 321. II. Neutron diffraction stress analysis at the IBR-2 pulsed nuclear reactor. Moscow: Joint Institute for Nuclear Research; 2007. E18-2007-111.

24. Msolli S, Martiny M, Cardoso MC, Moreira LP, Mercier S, Molinari A. Numerical modeling of the deformation of AISI 304L using a tangent additive Mori-Tanaka homogenization scheme: application to sheet metal forming. J Mater Process Technol. 2016;235:187-205.

25. Taran YV, Balagurov AM, Schreiber J, Evans A, Venter AM. Residual stresses in biaxially fatigued austenitic stainless steel sample of cruciform geometry. J Phys Conf Ser. 2012;340:012099.

26. Withers PJ, Bhadeshia HKDH. Overview: residual stress part 1measurement techniques. Mater Sci Technol. 2001;17(4):355-65.

27. Nezakat M, Akhiani H, Hoseini M, Szpunar J. Effect of thermomechanical processing on texture evolution in austenitic stainless steel 316L. Mater Charact. 2014;98:10-7.

28. Nezakat M, Akhiani H, Sabet SM, Szpunar J. Electron backscatter and X-ray diffraction studies on the deformation and annealing textures of austenitic stainless steel 310S. Mater Charact. 2017;123:115-27.

29. Raabe D. Texture and microstructure evolution during cold rolling of a strip cast and of a hot rolled austenitic stainless steel. Acta Mater. 1997;45(3):1137-1151.

30. Cakmak E, Vogel SC, Choo H. Effect of martensitic phase transformation on the hardening behavior and texture evolution in a 304L stainless steel under compression at liquid nitrogen temperature. Mater Sci Eng A. 2014;589:235-41. 